\title{
The transformation of green rusts coupled with the fate of phosphate and organic pollutants
}

\author{
LIPING FANG* AND FANGBAI LI
}

Guangdong Institute of Eco-Environ Sci \& Technol, Guangzhou 510650, China (lpfang@soil.gd.cn).

Green rusts (GRs) are the intermediate of iron biomineralization with a unique layered structure, with the general formula of $\left[\mathrm{Fe}^{\mathrm{II}}(1-x) \mathrm{Fe}^{\mathrm{III}}{ }_{x}(\mathrm{OH})_{2}\right]^{x+}\left[(x / n) \mathrm{A}^{n-}\right.$, $\left.m \mathrm{H}_{2} \mathrm{O}\right]^{x-}$. The transformation of GRs with the fluctuation of redox in soils is highly affected by phosphate (P) or organic pollutants in soils, while their coupled reaction and how this process affects the fate of nutrients and pollutants are poorly understood. Herein, this work investigated the effects of GRs on P release, and co-existing GR and $\mathrm{P}$ on pollutants degradation, and the transformation of GRs and the underlying mechanisms were addressed.

Our results show that the adsorption of $\mathrm{P}$ on GRs can suppress the GR oxidation by oxygen, while the $P$ release kinetic rate from GRs depends on the content of oxygen. The formation of vivianite phase in the presence of $\mathrm{P}$ restricts $\mathrm{P}$ release. Intriguingly, $\mathrm{P}$ significantly alters the GR reactivity towards 2,4chlorinated phenol $(2,4-\mathrm{CP})$ under oxic conditions; with the increase of $\mathrm{P}$, the $2,4-\mathrm{CP}$ oxidation rate increases. Results indicate that $\cdot \mathrm{OH}$ reactive oxygen species are mainly responsible for 2,4-CP oxidation. P stabilizing the structure of GRs, and enhancing the electron efficiency is the major cause for the improved 2,4-CP oxidation by GRs. This study provides additional understanding in coupling redox of GRs with $\mathrm{P}$ and organic pollutants in the environments.

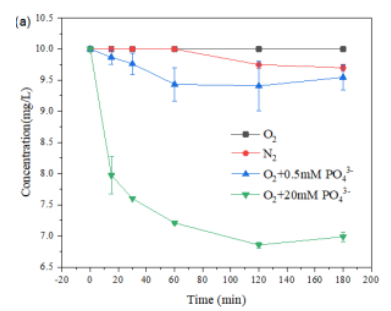

Fig. 1 the degradation of 2,4$\mathrm{CP}$ by GR in the presence and absence of $\mathrm{P}$ under anoxic and oxic conditions 